JICA

29,4

Received 18 May 2021 Revised 11 June 2021 Accepted 17 June 2021

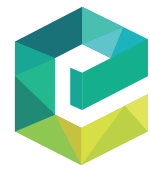

Journal of Integrated Care Vol. 29 No. 4,2021 pp. $390-402$ Emerald Publishing Limited 1476-9018 DOI 10.1108/JICA-04-2021-0018

\section{Patient experience and satisfaction with admission to an acute geriatric community hospital in the Netherlands: a mixed method study}

\author{
Marthe E. Ribbink
}

Department of Internal Medicine, Section of Geriatric Medicine, Amsterdam Public Health Research Institute, Amsterdam University Medical Centers, Location AMC, Amsterdam, The Netherlands

Catharina C. Roozendaal

Department of Medicine for Older People, Amsterdam Public Health Research Institute, Amsterdam University Medical Centers, Location VUmc, Amsterdam, The Netherlands, and

Janet L. MacNeil-Vroomen, Remco Franssen and Bianca M. Buurman Department of Internal Medicine, Section of Geriatric Medicine, Amsterdam Public Health Research Institute, Amsterdam University Medical Centers, Location AMC, Amsterdam, The Netherlands

\begin{abstract}
Purpose - The acute geriatric community hospital (AGCH) in an intermediate care facility is an alternative to conventional hospitalization. A comprehensive geriatric assessment and rehabilitation are integrated into acute medical care for older patients. This study aims to evaluate patient experience and satisfaction with the AGCH.

Design/methodology/approach - This is a mixed method observational study including a satisfaction questionnaire and qualitative interviews with $\mathrm{AGCH}$ patients or informal caregivers.

Findings - A total of 152 participants filled in the questionnaire, and thirteen semi-structured interviews were conducted. Twelve categories and four overarching themes emerged in the analysis. In general, study participants experience the admission to the AGCH as positive and are satisfied with the care they received; there were also suggestions for improvement.
\end{abstract}

(C) Marthe E. Ribbink, Catharina C. Roozendaal, Janet L. MacNeil-Vroomen, Remco Franssen and Bianca M. Buurman. Published by Journal of Integrated Care. Published by Emerald Publishing Limited. This article is published under the Creative Commons Attribution (CC BY 4.0) licence. Anyone may reproduce, distribute, translate and create derivative works of this article (for both commercial and noncommercial purposes), subject to full attribution to the original publication and authors. The full terms of this licence may be seen at http://creativecommons.org/licences/by/4.0/legalcode.

The authors would also like to thank the members of the AGCH study group; these are the clinicians who work at the Geriatrics Department of the Amsterdam University Medical Centers and/or the AGCH.

Funding: The acute geriatric community hospital (AGCH, Amsterdam University Medical Centers) research receives funding though ZonMw, the Netherlands Organization for Health Research and Development, project number 808393598041 and the PVE fund. Moreover, the care provided at the AGCH is provided in a partnership between Cordaan, a community and home-care organization and the Amsterdam University Medical Center, location Academic Medical Center. The AGCH is financially supported by Zilveren Kruis, a health insurance company.

Collaborators: The AGCH study group comprises R H A van den Broek; W J Frenkel; M J Henstra; M A van Maanen; C J M Melkert, J L Parlevliet; E P van Poelgeest; M N Resodikromo; K J Kaland; I Oudejans; P M A van Rijn; N van der Velde; H C Willems; D Wyatt. 
Research limitations/implications - Limitations of this study include possible participation bias. The results show that patients value this type of care indicating that it should be implemented elsewhere. Further research will focus on health outcomes, readmission rates and cost effectiveness of the AGCH.

Originality/value - This is the first study to evaluate care satisfaction with the AGCH. It shows that hospitalized older adults positively value the AGCH as an alternative to hospitalization.

Keywords Older adults, Hospitalization, Community hospital, Quality of care, Intermediate care

Paper type Research paper

\section{Introduction}

Hospital admission is a stressful event for older adults and their families. It is associated with deconditioning, functional decline, hospital readmissions and increased mortality (Boyd et al., 2008; Buurman et al., 2011). Furthermore, patients with geriatric syndromes such as delirium, malnutrition, depressive symptoms and functional impairment have an increased risk of functional decline, nursing home admission (Inouye et al., 1998) and readmission (Van Seben et al., 2017).

With an aim to prevent these negative outcomes, alternatives to conventional hospitalization have been developed (Conley et al., 2016). An example is hospital at home where a patient receives hospital treatment at home (Shepperd et al., 2008). Another alternative that was recently developed and opened in 2018 in Amsterdam, the Netherlands, is admission to a specialized acute geriatric unit in an intermediate care facility: the acute geriatric community hospital (AGCH) (Ribbink et al., 2020). In this new model, care patients are selected for admission at the emergency department (ED) of a general hospital and then transferred to the AGCH. Complete criteria for admission have been described elsewhere (Ribbink et al., 2020, 2021). At the AGCH, patients receive specialized treatment including a comprehensive geriatric assessment (Ellis et al., 2011) and early rehabilitation (Colprim et al., 2013). The patient care goals of the AGCH are firstly to improve self-efficacy (Boltz et al., 2014) and prevent functional decline (Boyd et al., 2008). It therefore has an adapted environment with single rooms and open hallways that allow for mobilization during the day. Also, patients receive physiotherapy and are encouraged to set daily goals, to promote self-efficacy and mobilization. Secondly, the AGCH aims to improve sleep by allowing informal caregivers to stay during the night and by preventing overstimulation. A continuous noncontact heart and respiration rate monitor (Early Sense ${ }^{\mathrm{TM}}$ ) (Brown et al., 2014) is used, which allows monitoring the patient's vital signs without waking the patient at night. Thirdly, the AGCH focuses on family and informal caregiver involvement (Pearson et al., 2015) and transitional care (Verhaegh et al., 2014); patients and their informal caregivers are involved in treatment and discharge planning. These interventions aim to improve clinical outcomes of care, improve patient and informal caregiver satisfaction with care and reduce costs. A prospective cohort study is underway to evaluate if the AGCH improves clinical and economic outcomes (Ribbink et al., 2020).

The current study evaluates the patient and informal caregiver experience and satisfaction with care. As the AGCH aims to involve patients and their caregivers in the care provided at the AGCH, the concept itself was also developed iteratively together with older adults living in the community. Nineteen patients and their informal caregivers were interviewed about the AGCH concept during the development phase of the project. In these interviews, the interviewees expressed that they would like the AGCH to be a small-scale unit, providing patient-centered care that provided support for informal caregivers. However now that the AGCH has opened, we do not know how older adults experience admission to the $\mathrm{AGCH}$. This is relevant as patient experience has been linked to the quality-of-care pathways (Flott et al., 2018), and we would like to evaluate if patients and caregivers are indeed satisfied with the care that they received. Our study aim was therefore to gain insight into the patient experience and to describe patient satisfaction with admission to the AGCH. We wanted to understand what experiences, processes or circumstances led to patients being (dis)satisfied
Acute geriatric community hospital 
JICA

29,4

392

with the received care. The outcomes of this study will be used to further improve the AGCH concept and to evaluate if the AGCH concept should be implemented elsewhere.

We used a mixed method design where we analyzed responses to a questionnaire and conducted qualitative semi-structured interviews with a selected group of patients. During the initiation phase of this research, we developed a conceptual framework of the patient experience within the AGCH. This framework was used to guide interviews (Figure 1).

\section{Methods}

Study design

Participants 65 years and older were enrolled in a prospective controlled study evaluating the effectiveness of care delivery at the AGCH. The full protocol of this study has been described elsewhere (Ribbink et al., 2020). Data collection for this study started in February 2019 and was temporarily ceased in March 2020 during the coronavirus disease 2019 (COVID-19) pandemic. Data collection, both quantitative as well as qualitative, on patient experience and satisfaction was not recommenced during the pandemic because (1) in-person interviews were no longer allowed and (2) patient experience was heavily impacted by COVID-19 restrictions because, for example, patients could no longer receive visitors.

We conducted a mixed-method study because using both quantitative as well as qualitative methods can improve study validity (Guion, 2002). This is sometimes referred to as method triangulation. Hence, this mixed method study evaluates (1) the quantitative secondary outcome patient and caregiver satisfaction using a satisfaction questionnaire and

Patient experience of admission to the Acute Geriatric Community Hospital (AGCH)

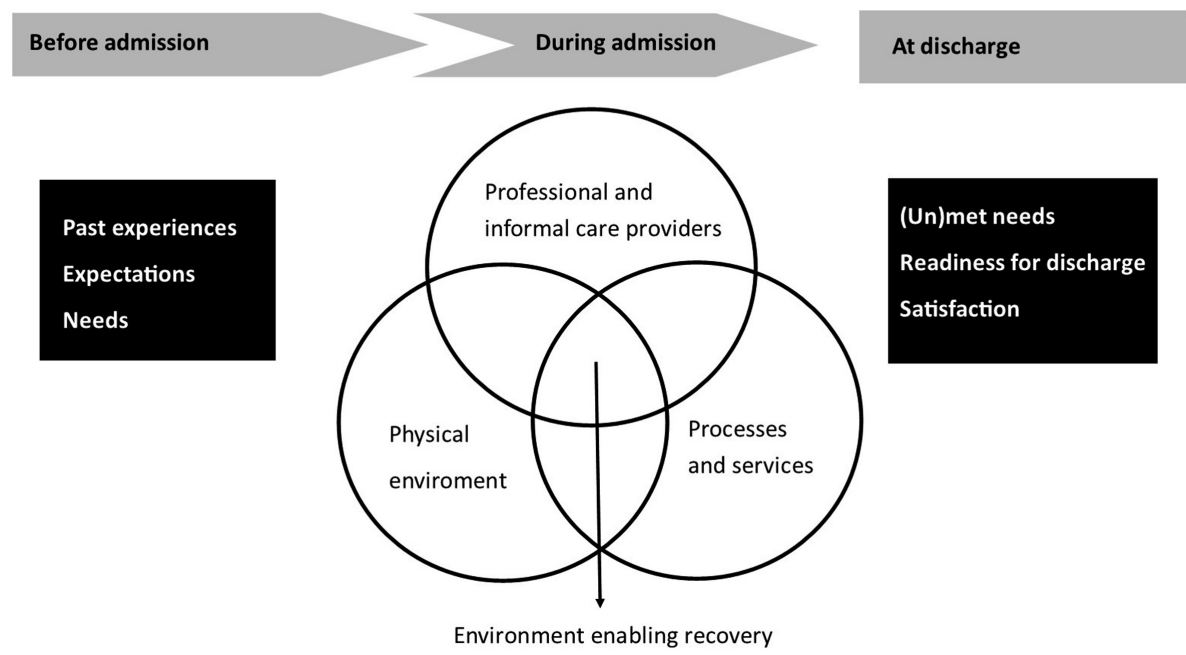

Note(s): Before admission patients have already formed medical experiences, expectations and needs, these terms have been previously been described for the experience in long term care by

Figure 1.

This conceptual framework was created to explain the experience of patients admitted to the $\mathrm{AGCH}$ Sion et al. (2019) When they are admitted there are both professional care providers (nurses, therapists, doctors) and informal care providers (family members, friends), processes and services (admission via ambulance, food and daily schedule) and the environment (single room, quiet hallways, space to move around) that we associate with an environment that enables recovery (Boltz et al., 2010). If patients "needs are met or not met during admission this will lead to (un)met needs (Holland et al., 2011), (un)readiness for discharge (Verhaegh et al., 2019) and a feeling of (dis)satisfaction (Sion et al., 2019) terms from previous literature 
(2) the patient experience and satisfaction studied using qualitative methods. The questionnaire contained six Likert-scale questions (Figure 2), an overall satisfaction score $(0-10)$ and one open-ended question: "Do you have any remarks or comments regarding your stay at the AGCH?" The results from the questionnaire were analyzed and used as input for a more thorough qualitative analysis of the patient experience and satisfaction with care at the AGCH. We decided to do this because the answers to the open-ended question provided insight into patient satisfaction but were not in-depth descriptions of patient experience. Therefore, we conducted, more in-depth, semi-structured interviews, ect., and used the answers to the open-ended question to triangulate our findings. We used the consolidated criteria for reporting qualitative research (COREQ) checklist (Tong et al., 2008) to ensure all relevant items for reporting qualitative research were included (checklist in supplementary appendix).

\section{Qualitative interviews}

Patients were eligible for participation in a semi-structured interview if they (1) were participants in this prospective controlled cohort study and (2) did not have cognitive impairment, that is, the patient should be able to provide informed consent for the interview and audio recording, or (3) had an informal caregiver who agreed to act as a proxy for the interview. A purposeful sampling method was used, where we aimed for variation in age, gender, previous occupation and/or level of education of the patient. For the final interviews we asked informal caregivers of patients with cognitive impairment to partake in an interview.

We wanted to understand the patient experience from a chronological time-path, the patient journey (Trebble et al., 2010), from admission to discharge home. Therefore, we created a conceptual framework (Figure 1) and interview guide that followed this patient journey. In addition, we used answers from the questionnaire to add topics that seemed particularly relevant to the patient experience, for example, "food and meals" was a topic which had not been initially included in the interview guide but one that was repeatedly mentioned by participants. The guide was discussed by the research team prior to the first pilot interview. After two pilot interviews, the interview guide was reviewed and adjusted by MER and CCR. During data collection, minor alterations and additions were made to the interview guide.

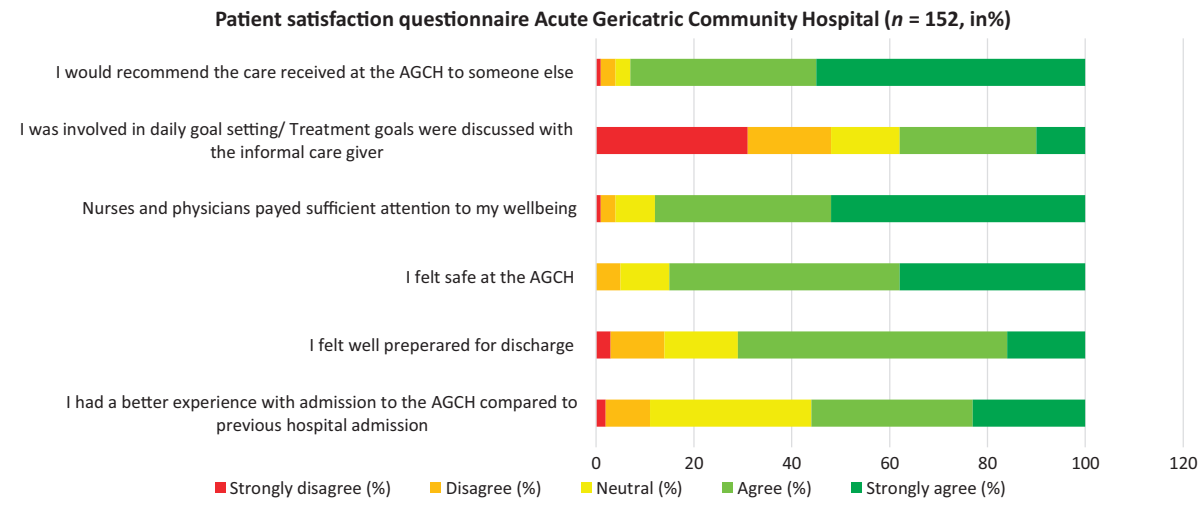

Note(s): See appendix table for full results of the patient satisfaction questionnaire

Source(s): Likert (1932)
Acute geriatric community hospital

393

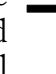


JICA

29,4

394

Interviews were scheduled between $48 \mathrm{~h}$ prior to discharge and two weeks post-discharge. Based on the patient's preference, the interview was conducted at the AGCH or at the patient's home. The presence of an informal caregiver was discussed, and verbal informed consent was obtained when an informal caregiver was present during the interview. Their input was included in the data although we focused on analyzing the data from the patient's viewpoint. The interviews were all audio recorded. There were no repeat interviews. The audio-recorded interviews were transcribed verbatim and anonymized. During and after the interview, field notes were made to capture impressions of and thoughts on the interview. Transcripts were not returned to participants, and no participant checking was performed.

\section{Qualitative analysis}

We conducted a thematic analysis following the steps described by Braun and Clarke (2006). For the first six semi-structured interviews, we used an open-coding approach. MER and CCR separately coded these interviews. After discussing the codes thoroughly, an initial coding structure was created. We used the conceptual framework (Figure 1) to guide us in creating this coding structure. The remaining interviews were coded using the initial coding structure; if relevant, new codes were included in the second coding structure. After all the interviews were coded, MER and CCR reviewed the second coding structure and identified all relevant categories and themes. If there was not enough data to support initial categories, they were removed. Finally, MER and CCR agreed on a final coding structure, categories and overarching themes. MAXQDA 2020 (VERBI Software, 2019) software was used for coding. We did aim for saturation but could not assure saturation on all topics because the study was not recommenced after the start of the COVID-19 pandemic.

\section{Research team and contributions}

The interviews and analysis were conducted by MER and CCR. MER is a $\mathrm{PhD}$ candidate who received training in qualitative research. At the time of conducting this research, CCR was a sixth-year medical student with no prior training in qualitative research. JMV, RF and BMB are senior researchers who oversaw the design and conduct of the study. $\mathrm{RF}$ is an internist working at the ED and AGCH.

\section{Ethical considerations}

The Medical Ethics Research Committee of the Amsterdam University Medical Centers confirmed that the Medical Research Involving Human Subjects Act did not apply to this research project, and official approval was not required.

\section{Results}

Between February 2019 and March 2020, 239 participants, were recruited for the questionnaire study (Figure 2). Out of these 239, 152 participants answered the questionnaire; a further 123 participants provided an answer to the open-ended question. Mean age in the group of patients who answered the questionnaire was 81.1 (standard deviation 8.4$)$ years, $51.3 \%(n=78)$ were female, and in $23.7 \%(n=36)$ of cases, an informal caregiver partook in the study on behalf of the patient. Participants rated their satisfaction with the AGCH with a score of 8.1 out of 10 .

For the semi-structured interviews, 13 participants were included between September 1, 2019 and March 11, 2020 (Table 1). Seventeen were purposefully selected and approached for participation in an interview. Four declined participation. Three additional participants were selected but not approached for an interview during the start of the COVID-19 pandemic. Interviews lasted 30-80 min. Mean age of the 13 participants was 79 years (range 6594 years) (Table 1). We identified 12 categories with four overarching themes (Table 2). 


\begin{tabular}{|c|c|c|c|c|c|c|c|}
\hline & $\begin{array}{c}\text { Age } \\
\text { (years) }\end{array}$ & Gender & $\begin{array}{l}\text { Marital status } \\
\text { Living } \\
\text { situation } \\
\end{array}$ & Diagnosis & $\begin{array}{l}\text { Length of } \\
\text { stay (days) }\end{array}$ & $\begin{array}{l}\text { Caregiver present } \\
\text { during the } \\
\text { interview }\end{array}$ & $\begin{array}{r}\text { Acute geriatric } \\
\text { community } \\
\text { hospital }\end{array}$ \\
\hline $\mathrm{P} 1$ & 77 & $\mathrm{~F}$ & $\begin{array}{l}\text { Widow - living } \\
\text { alone }\end{array}$ & Hyponatraemia & 10 & No & \\
\hline $\mathrm{P} 2$ & 65 & $\mathrm{~F}$ & $\begin{array}{l}\text { Widow - living } \\
\text { alone }\end{array}$ & $\begin{array}{l}\text { Pneumonia, heart } \\
\text { failure }\end{array}$ & 6 & No & 395 \\
\hline P3 & 78 & $\mathrm{~F}$ & $\begin{array}{l}\text { Unmarried - } \\
\text { living alone }\end{array}$ & Urinary tract infection & 4 & Not applicable & \\
\hline $\mathrm{P} 4$ & 80 & $\mathrm{M}$ & $\begin{array}{l}\text { Widower - } \\
\text { living alone }\end{array}$ & Exacerbation COPD & 12 & Not applicable & \\
\hline P5 & 90 & $\mathrm{M}$ & $\begin{array}{l}\text { Widower - } \\
\text { living alone }\end{array}$ & Heart failure & 7 & No & \\
\hline $\mathrm{P} 6$ & 79 & M & $\begin{array}{l}\text { Living with a } \\
\text { partner }\end{array}$ & $\begin{array}{l}\text { Urinary tract infection, } \\
\text { delirium }\end{array}$ & 10 & No & \\
\hline $\mathrm{P} 7$ & 68 & M & $\begin{array}{l}\text { Living with a } \\
\text { partner }\end{array}$ & Exacerbation COPD & 7 & No & \\
\hline P8 & 72 & $\mathrm{~F}$ & $\begin{array}{l}\text { Living with a } \\
\text { partner }\end{array}$ & $\begin{array}{l}\text { Post-pneumonial } \\
\text { bronchial } \\
\text { hyperreactivity }\end{array}$ & 11 & Yes, partner & \\
\hline P9 & 72 & $\mathrm{~F}$ & $\begin{array}{l}\text { Living with a } \\
\text { partner }\end{array}$ & Exacerbation COPD & 9 & Yes, partner & \\
\hline $\mathrm{P} 10$ & 74 & M & $\begin{array}{l}\text { Unmarried - } \\
\text { living alone }\end{array}$ & Fracture & 10 & Not applicable & \\
\hline P11 & 94 & $\mathrm{M}$ & $\begin{array}{l}\text { Living with a } \\
\text { partner }\end{array}$ & Heart failure & 5 & $\begin{array}{l}\text { Yes, partner and } \\
\text { son }\end{array}$ & \\
\hline P12 & 92 & $\mathrm{~F}$ & $\begin{array}{l}\text { Unmarried - } \\
\text { living alone }\end{array}$ & Fall, delirium & 22 & Yes, daughter & \\
\hline $\mathrm{P} 13$ & 86 & $\mathrm{~F}$ & $\begin{array}{l}\text { Living with a } \\
\text { partner }\end{array}$ & $\begin{array}{l}\text { Urinary tract infection, } \\
\text { delirium }\end{array}$ & 29 & Yes, daughter & $\begin{array}{r}\text { Participant } \\
\text { characteristics }\end{array}$ \\
\hline
\end{tabular}

\begin{tabular}{|c|c|c|}
\hline Category & Theme & \\
\hline 1. Acute medical needs & \multirow[t]{2}{*}{ Visiting the emergency department } & \\
\hline 2. Care process at the emergency department & & \\
\hline 5. The physical environment of the AGCH & \multirow[t]{3}{*}{ The experience of the AGCH admission } & \\
\hline 6. Care processes and important persons & & \\
\hline $\begin{array}{l}\text { 7. Recovering from illness, remaining independent } \\
8 \text {. Views on the AGCH }\end{array}$ & & \\
\hline 9. Comparison to care in a general acute hospital & Satisfaction with the AGCH concept & $\begin{aligned} & \text { Table } 2 . \\
& \text { Categories and }\end{aligned}$ \\
\hline 10. Suggested improvements for the AGCH & \multirow{3}{*}{ Going home, being home } & overarching themes \\
\hline 11. Home and primary care & & concerning the AGCH \\
\hline 12. Discharge home & & care pathway \\
\hline
\end{tabular}

Theme 1 - visiting the emergency department

Most participants indicated that they did not remember all that had passed at the ED, but all could describe the reasons for visiting the ED. Three categories emerged: acute medicalneeds, the care process at the ED and satisfaction with the care provided, and expectations of the $A G C H$. 
JICA

29,4

396

Acute medical needs. Participants were sent to the ED by a general practitioner, after consulting a medical specialist or after family members had called for an ambulance. Patients experienced a range of symptoms, but many either had pain or were short of breath:

The GP service came by and they did not think it was responsible. ... that I was short of breath, that they brought me there [to the emergency department] - Interview 2

Most suffered from exacerbations of chronic conditions such as an exacerbation of chronic obstructive pulmonary disease (COPD) or heart failure (Table 1 - participant characteristics). In many cases, their symptoms had emerged in the past few days or had worsened in the past $24 \mathrm{~h}$. Once at the ED, many participants felt that their symptoms improved because they were attended to and were now in "good hands".

Care process at the emergency department. The ED was often described as a busy place. There was not always an informal caregiver present. Participants were generally quickly attended to, but then had to wait a long time before they could be admitted:

I was there for over six hours, before I came here [the AGCH] it was already six pm, so I came there [the $\mathrm{ED}$ ] at quarter to two in the afternoon I believe, so I was lying there [on a stretcher] for quite a long time. - Interview 3

Satisfaction with the care provided and expectations of the AGCH. Not all participants felt they were consulted about the decision to be admitted to the AGCH. This was however not experienced as burdensome. Participants usually did not know what to expect from the AGCH:

Then the doctor came and said: we will transfer you to the AGCH. Well, for me that was a big question mark, I had never heard of it. - Interview 11

They received a leaflet and information about the AGCH from a physician or nurse at the ED, which was considered sufficient. Many expected to be admitted to a hospital department, but then did not recognize the AGCH as a hospital department:

Well, I was expecting to go to some sort of hospital, how terrible. But that was not how I felt once I was here. - Interview 1

Participants did not mind the transition to the AGCH by an ambulance. An unmet need was the need to drink or eat during the stay at the ED; many reported to be very hungry, thirsty and tired once they arrived at the AGCH.

\section{Theme 2: the experience of the AGCH admission}

Three categories within the theme experience of AGCH admission emerged: The physical environment of the AGCH, care processes and important persons at the $A G C H$, and recovering from illness, remaining independent.

The physical environment of the AGCH. The physical environment of the AGCH is the first thing many participants mention. They describe a hotel-like environment with a single room, a comfortable bed and a personal bathroom. Many participants recognized that the department had been recently renovated. Furthermore, they described it as a quiet environment, where they could sleep well most nights. When asked, most participants felt safe from a medical perspective and felt that they would be quickly attended to in case of medical emergency. The Early Sense ${ }^{\mathrm{TM}}$ monitor did not improve their sense of safety per se; they did however not mind being monitored continuously:

Well, they [the nurses] cannot ... they cannot be by your bedside all night. A sensor like this is perfect for people ... confused people and so on. Because then they [the nurses] are warned and they come. No, I think it is an excellent idea. - Interview 6 
With regards to access to the department and patient rooms, it was was experienced to be unsafe at times because the department was freely accessible and there was no doorman or reception. Some patients did not leave the department during their stay at the AGCH. Others used the restaurant or made walks in the garden. Overall, participants felt that the AGCH, compared to a general hospital, had more of a "home-like" environment.

Processes and important persons at the AGCH. Nurses were the most important persons for participants during their stay at the AGCH. Patients describe the nurses to be involved, wanting to genuinely care for the patient and friendly:

(...) I am really positive about the way in which nurses approach their patients. (...) How approachable and how willingly they are to help. That was exemplary. - Interview 11

Doctors were more in the background. Multiple participants found themselves "medically unskilled" but trusted doctors to be competent and present when needed. Not all participants received physiotherapy. One participant had not recognized the therapy session as physiotherapy. Other participants were satisfied with the physiotherapy and the frequency of sessions.

Recovering from illness. All participants described a noticeable recovery during their stay. Physiotherapy was seen as useful, especially for improving their functioning in daily life. Some participants felt the medical treatment and their personal motivation was most important for their recovery, not the involvement of care professionals:

Was there someone who helped you in the process of recovery? Well, honestly, I myself, I have to, I am not going to just give up, I cannot. - Interview 2

The phrase "the will to be independent" was used by multiple participants to describe that they themselves oversaw their recovery.

All participants talked about the food in the AGCH. Opinions on the quality of the food differed. Participants mentioned that food was important for their recovery. Some felt that not enough information and guidance on healthy eating was provided.

\section{Theme 3: satisfaction with the AGCH concept}

Views on the AGCH. In general, patients were positive about the AGCH and the concept of the AGCH. Participants described the AGCH as a place to receive treatment and recover, after which they would go back home. Participants who lived nearby liked that visiting was easier for their relatives. Many thought the AGCH a good alternative for hospitalization or as a "step" between hospital and home. Participants thought that the AGCH would lead to lower health-care costs and a reduced burden on the hospital:

A great concept. (...) I think it is a solution in its purest form. The size of the neighbourhood is not up to me, I believe there is a professor at the [University Hospital] who thought of this, but I think every neighbourhood should have such an AGCH.(. ..) Just for people like me, I do not have to go to hospital, costing thousands of euro's a day, but an AGCH, great! Yes, I think it is very well indeed. Interview 6

Comparison to care in a general hospital. Compared to a hospital, the AGCH's rooms where bigger and patients got more rest, which allowed for a better recovery. However, the hospital was more open and allowed for contact with other patients. Most participants felt they received more personal attention from nurses and physicians in the AGCH:

Well, I would prefer to go to the AGCH! Firstly, they will help you in a more personal manner, of course they cannot help that in the hospital. There, there are at least four patients per room and if you have room to yourself, you are lucky. They cannot give you the same attention, as they give you here. - Interview 8 
JICA

29,4

398

There were less doctors and no medical students during rounds which patients perceived as positive. A "white tornado" of doctors and medical students (in a general hospital) was perceived as not personal and not allowing the patient to partake in decision-making. Participants felt that they and their informal caregivers were more involved in decisionmaking. Some participants felt that they were not involved in decision-making, especially regarding their discharge date and discharge location. However, there was no clear difference in received medical care; some stated services in the hospital were more punctual, for example, with handing out medication:

Well, maybe you think less about being ill when you are here [at the ACGH]. But I feel fine in a hospital as well. It does not matter to me. (...) If someone looks out for you, then for me it is fine. (laughs). If I get my medication [on time] then for me, it is totally fine. - Interview 3

Some participants observed that the provided care at the AGCH was less complex compared to a general hospital. Multiple participants thought the personnel at the AGCH had a lower level of education. The lower level of care provided at the AGCH compared to a hospital did however suffice. Finally, free parking at the AGCH was considered a benefit.

Suggested improvements for the AGCH. Most participants did not have specific suggestions for the AGCH and regarded adverse events as so minor that they should not receive any attention from the interviewers. Some could identify several unmet needs or suggestions for improvement of the AGCH.

These unmet needs were "lack of information", "lack of activities", "lack of contact with other patients" and goals of the AGCH being too ambitious. Lack of information concerned lack of information provided by the staff about medication, nutrition and exercise. Especially with regards to medication, patients would like to be informed better. Some participants experienced staff to not always be up to date on decisions that had been made. With regards to lack of activities and lack of contact with other patients, a participant stated,

What did you think of activities? Well, that, television, you do not have anything else. - Interview 5

Once they felt better, some participants described the AGCH to be boring and not stimulating. However, some participants did not want any special activities, as they would go home soon. No participant had contact with other patients because of the single rooms. However, half of the participants would have liked some contact. Finally, some caregivers thought that the goals set by the AGCH were perhaps too ambitious. One participant had a goal of walking 500 meters, whereas he could only walk less than 100 meters preadmission. Some of the practical improvements were adding handlebars in the shower and/or adding a curtain for more privacy to the room. Moreover, the location and naming of the AGCH was not always clear to visitors. A reception to the AGCH was a suggested improvement. Some were not satisfied with the cleaning of the room.

\section{Theme 4: going home, being home}

Home and primary care. When talking about their living situation, many participants stated the wish to remain in their own house and to be independent for as long as possible. Most participants relied on the care of professional or informal caregivers in some way. Participants usually did not want to impose on their family members; however, direct family was the primary source of support. Some of the participants did not receive any home care before admission, but after discharge many started to receive home care.

Discharge home. Discharge was a topic that was most clearly associated with miscommunication and unmet needs. Some experienced difficulties with their changed medication or even reported medication errors. Miscommunication about discharge concerned the date and time of discharge and the possibility that discharge could be 
postponed. Many participants experienced they were informed late about their upcoming discharge, feeling rushed and not ready to go home. This feeling was caused either by uncertainty about their physical state and the wish to train more with the physiotherapist before returning home, or because participants felt that home care and medication had not been organized well enough. Proxy-interviewees stated that the moment of discharge came unexpected because in the final days of admission there was less contact with the doctors.

Nevertheless, many of the participants stated that they were happy to be home once they were discharged. However, most of the participants did not feel fully recovered yet:

Acute geriatric community hospital

Yes I was happy to go home. Could you manage once you were home? (. . .) Well, not exactly (. . .) I do want to remain independent however. So you did manage? Yes, but, slowly and with a lot of effort. Interview 2

\section{Discussion}

This mixed-method study showed that patients generally experience the admission to the AGCH as positive. The care pathway of the AGCH, which starts at the ED, was considered well-organized up to discharge. During discharge, there were some unmet needs, and an unexpected change in the discharge date could overwhelm and dissatisfy participants. However satisfactory experiences strongly outweighed dissatisfactory experiences in our analysis. There were also suggested improvements for the AGCH which concerned practical problems and the request for more information from doctors and nurses. Nevertheless, most participants would support the opening of more AGCHs and tend to prefer admission to the AGCH to admission in a general acute hospital.

When we compare the quantitative to the qualitative data, these are generally consistent; however, in the questionnaire that was conducted mostly prior to the interviews, we see that many of the participants had not been involved in daily goal-setting. Interestingly this was not one of the subjects that was mentioned in the interviews, and it did not seem to influence how participants experienced their recovery. Personal motivation and "the will to be independent" were important to participants and were perceived as the main drivers of recovery. Even so, the physiotherapists - who are explicit in setting treatment goals - were seen as important persons who aided recovery. It is known that in a geriatric population, goal setting can be difficult, and therefore it is possible that professionals at the AGCH do use (daily) goal-setting, but that patients did not understand or recognize these goals because they were, for example, not patient-centered enough (Leach et al., 2010, Van Seben et al., 2019).

The categories we found in our qualitative analysis are like themes Green et al. identified when comparing patient and caregiver experiences with a community hospital and a general hospital (Green et al., 2008). Green et al. identified amongst other themes the theme of the community hospital environment ("home-like" place) and location (accessible and free parking), staff attitude and activities. In the community hospital patients did not experience a lack of activities, as was the case in the AGCH.

Similar to what was reported by Small et al. (2007), interviewees at the AGCH did not talk much about the medical treatment they received but how, when and by whom care was delivered. Small et al. called this the "soft process" (Small et al., 2007). This differs from the "hard process" that doctors and nurses focus on: what training or treatment is given. Patients commented they were medically unskilled and therefore could not say anything useful about experiences with their medical treatment; however, they had great trust in the attending physician. Some participants or informal caretakers were more critical of medical treatment; this mostly concerned lack of information about treatment goals and changes in medication. 
JICA

29,4

\section{Limitations}

One of the studies' limitations is that some patients were interviewed about their experience with the AGCH until after the admission. This may have led to recall bias, especially for the phase at the ED. Another limitation is we could not conduct further interviews and check for saturation. The COVID-19 pandemic also restricted us in interviewing even more very frail patients and/or their informal caregiver as a proxy. These patients may have other needs compared to those who are relatively more resilient and have less memory problems. Furthermore, patients who were not satisfied or had negative experiences with the AGCH might have declined to participate in the cohort or qualitative study.

\section{Implications for clinical practice}

This study shows that older adults who need to be hospitalized value the AGCH concept as an alternative to hospitalization. Nevertheless, participants had suggestions for improvements, which will be and have been taken into consideration by the staff of the AGCH. For example, within the theme of the physical environment of the $A G C H$, the need for a reception was mentioned; this reception now has been installed at the AGCH. When looking just at satisfaction with care, our research results support the implementation of the AGCH concept and/or interventions elsewhere in the Netherlands and support the opening of similar models of care abroad. Further research will focus on outcomes such as the three-month unplanned readmission rate, incidence of functional decline, and cost-effectiveness of the AGCH. If the AGCH concept is implemented elsewhere in the Netherlands, research evaluating patient experience and satisfaction can be repeated to see if the concept is also experienced as positive when implemented at another location in the Netherlands.

\section{Conclusion}

This mixed-method study provides an insight into patient experiences and satisfaction with the AGCH, a unique acute geriatric care facility in the Netherlands. These qualitative outcomes are favorable, with most older persons preferring admission to AGCH to admission in a general hospital. However, further research on health outcomes, readmission rates and cost effectiveness of the AGCH is needed to complete the evaluation of the AGCH, and conclude if implementation elsewhere is indeed advisable.

\section{References}

Boltz, M., Capezuti, E., Shabbat, N. and Hall, K. (2010), "Going home better not worse: older adults' views on physical function during hospitalization”, International Journal of Nursing Practice, Vol. 16, pp. 381-388.

Boltz, M., Resnick, B., Capezuti, E. and Shuluk, J. (2014), "Activity restriction vs. self-direction: hospitalised older adults' response to fear of falling", International Journal of Older People Nursing, Vol. 9, pp. 44-53.

Boyd, C.M., Landefeld, C.S., Counsell, S.R., Palmer, R.M., Fortinsky, R.H., Kresevic, D., Burant, C. and Covinsky, K.E. (2008), "Recovery of activities of daily living in older adults after hospitalization for acute medical illness", Journal of the American Geriatrics Society, Vol. 56, pp. 2171-2179.

Braun, V. and Clarke, V. (2006), "Using thematic analysis in psychology", Qualitative Research in Psychology, Vol. 3, pp. 77-101.

Brown, H., Terrence, J., Vasquez, P., Bates, D.W. and Zimlichman, E. (2014), "Continuous monitoring in an inpatient medical-surgical unit: a controlled clinical trial", The American Journal of Medicine, Vol. 127, pp. 226-232.

Buurman, B.M., Hoogerduijn, J.G., DE Haan, R.J., Abu-Hanna, A., Lagaay, A.M., Verhaar, H.J., Schuurmans, M.J., Levi, M. and De Rooij, S.E. (2011), "Geriatric conditions in acutely 
hospitalized older patients: prevalence and one-year survival and functional decline”, PLoS ONE, Vol. 6, e26951.

Colprim, D., Martin, R., Parer, M., Prieto, J., Espinosa, L. and Inzitari, M. (2013), "Direct admission to intermediate care for older adults with reactivated chronic diseases as an alternative to conventional hospitalization", Journal of the American Directors Association, Vol. 14, pp. 300-302.

Conley, J., O’brien, C.W., Leff, B.A., Bolen, S. and Zulman, D. (2016), “Alternative strategies to inpatient hospitalization for acute medical conditions: a systematic review", Journal of the American Medical Association Internal Medicine, Vol. 176, pp. 1693-1702.

Ellis, G., Whitehead, M.A., Robinson, D., O'neill, D. and Langhorne, P. (2011), “Comprehensive geriatric assessment for older adults admitted to hospital: meta-analysis of randomised controlled trials", BMJ, Vol. 343, p. d6553.

Flott, K., Darzi, A. and Mayer, E. (2018), "Care pathway and organisational features driving patient experience: statistical analysis of large NHS datasets", BMJ Open, Vol. 8, p. e020411.

Green, J., Forster, A., Young, J., Small, N. and Spink, J. (2008), "Older people's care experience in community and general hospitals: a comparative study", Nursing Older People, Vol. 20, pp. 33-39, quiz 40.

Guion, L.A. (2002), Triangulation: Establishing the Validity of Qualitative Studies, This publication is FCS6014, one of a series of the Department of Family, Youth and Community Sciences, Florida Cooperative Extension Service, Institute of Food and Agricultural Sciences, University of Florida. Publication: September 2002.

Holland, D.E., Mistiaen, P. and Bowles, K.H. (2011), "Problems and unmet needs of patients discharged "home to self-care”, Professional Case Management, Vol. 16, pp. 240-250, quiz 251-2.

Inouye, S.K., Rushing, J.T., Foreman, M.D., Palmer, R.M. and Pompei, P. (1998), "Does delirium contribute to poor hospital outcomes? A three-site epidemiologic study", Journal of General Internal Medicine, Vol. 13, pp. 234-242.

Leach, E., Cornwell, P., Fleming, J. and Haines, T. (2010), "Patient centered goal-setting in a subacute rehabilitation setting", Disability and Rehablitation, Vol. 32, pp. 159-172.

Likert (1932), “A technique for the measurement of attitudes", Archives of Psychology, Vol. 140, pp. 1-55.

Pearson, M., Hunt, H., Cooper, C., Shepperd, S., Pawson, R. and Anderson, R. (2015), "Providing effective and preferred care closer to home: a realist review of intermediate care", Health and Social Care in the Community, Vol. 23, pp. 577-593.

Ribbink, M.E., Macneil-Vroomen, J.L., Van Seben, R., Oudejans, I. and Buurman, B.M. (2020), "Investigating the effectiveness of care delivery at an acute geriatric community hospital for older adults in the Netherlands: a protocol for a prospective controlled observational study", BMJ Open, Vol. 10, p. e033802.

Ribbink, M.E., Gual, N., Macneil-Vroomen, J.L., Ars Ricart, J., Buurman, B.M., Inzitari, M. and Group, A.G.-S. (2021), "Two European examples of acute geriatric units located outside of a general hospital for older adults with exacerbated chronic conditions", Journal of the American Medical Directors Association, Vol. 22 No. 6, pp. 1228-1234.

Shepperd, S., Doll, H., Angus, R.M., Clarke, M.J., Iliffe, S., Kalra, L., Ricauda, N.A. and Wilson, A.D. (2008), "Admission avoidance hospital at home", Cochrane Database of Systematic Reviews, p. CD007491.

Sion, K.Y.J., Haex, R., Verbeek, H., Zwakhalen, S.M.G., Odekerken-Schroder, G., Schols, J. and Hamers, J.P.H. (2019), "Experienced quality of post-acute and long-term care from the care recipient's perspective-A conceptual framework", Journal of the American Medical Directors Association, Vol. 20, pp. 1386-1390 e1.

Small, N., Green, J., Spink, J., Forster, A., Lowson, K. and Young, J. (2007), "The patient experience of community hospital-the process of care as a determinant of satisfaction", Journal of Evaluation in Clinical Practice, Vol. 13, pp. 95-101.

Acute geriatric community hospital 
JICA 29,4

Tong, A., Sainsbury, P. and Craig, J. (2008), "Consolidated criteria for reporting qualitative research (COREQ): a 32-item checklist for interviews and focus groups", International Journal for Quality in Health Care: Journal of the International Society for Quality in Health Care/ISQua, Vol. 19, pp. 349-357.

Trebble, T.M., Hansi, N., Hydes, T., Smith, M.A. and Baker, M. (2010), "Process mapping the patient journey: an introduction", BMJ, Vol. 341, p. c4078.

Van Seben, R., Reichardt, L.A., Aarden, J., Van Der Schaaf, M., Engelbert, R., Bosch, J. and Buurman, B. (2017), "Geriatric syndromes from admission to 3 months post-discharge and their association with recovery", Innovation in Aging, Vol. 1, pp. 902-903.

Van Seben, R., Smorenburg, S.M. and Buurman, B.M. (2019), "A qualitative study of patient-centered goal-setting in geriatric rehabilitation: patient and professional perspectives", Clinical Rehabilitation, Vol. 33, pp. 128-140.

Verhaegh, K.J., Macneil-Vroomen, J.L., Eslami, S., Geerlings, S.E., De Rooij, S.E. and Buurman, B.M. (2014), "Transitional care interventions prevent hospital readmissions for adults with chronic illnesses", Health Affairs (Millwood), Vol. 33, pp. 1531-1539.

Verhaegh, K.J., Jepma, P., Geerlings, S.E., De Rooij, S.E. and Buurman, B.M. (2019), "Not feeling ready to go home: a qualitative analysis of chronically ill patients' perceptions on care transitions", International Journal for Quality in Health Care, Vol. 31, pp. 125-132.

\section{Appendix}

Appendixes of this article are included in a supplementary document which is available at

\section{Corresponding author}

Marthe E. Ribbink can be contacted at: m.e.ribbink@amsterdamumc.nl

For instructions on how to order reprints of this article, please visit our website:

www.emeraldgrouppublishing.com/licensing/reprints.htm

Or contact us for further details: permissions@emeraldinsight.com 